\title{
Percepções estéticas de mulheres lésbicas acerca de produtos de sex shop
}

\section{Aesthetic perceptions of lesbian women about sex shop products}

\author{
Mariana Luísa Schaeffer Brilhante \\ Mestranda em Design do Vestuário e Moda pela Universidade do estado de Santa Catarina (UDESC) - \\ marsbxx@gmail.com - orcid.org/0000-0003-1708-1487 \\ Célio Teodorico dos Santos \\ Doutor em Engenharia Mecânica pela Universidade Federal de Santa Catarina(UFSC) - \\ celio.teodorico@gmail.com - orcid.org/0000-0001-9809-5658
}

\begin{abstract}
Resumo
Este artigo busca entender as percepções estéticas de mulheres lésbicas acerca de produtos de sex shop. Assim, esta é uma pesquisa exploratória, básica e descritiva, que se desenvolveu a partir de pesquisa de campo com entrevistas, utilizando um questionário semiestruturado. Esse questionário foi aplicado em grupos focais, de maneira on-line e presencial, sendo a análise desses dados desenvolvida de forma qualitativa. No caso deste estudo, foi possível identificar que as percepções estéticas de mulheres lésbicas acerca de produtos de sex shop seguem desde uma relação de poder com a parceira até uma relação de estranheza com o objeto, gerando possíveis desconfortos. Ainda, tanto na pesquisa on-line quanto na pesquisa presencial, foi possível identificar que há uma preferência por sex toys fálicos e com cores e formas artificiais.
\end{abstract}

Palavras-chave: Brinquedos sexuais. Lésbicas. Indústria do sexo. Percepção de padrões.

\section{Abstract}

This article seeks to understand the aesthetic perceptions of lesbian women about sex shop products. Thus, this is an exploratory, basic and descriptive research, which was developed from field research with interviews, using a semi-structured questionnaire. This questionnaire was applied to focus groups, both online and in person, and the analysis of these data was carried out in a qualitative way. In the case of this study, it was possible to identify that the aesthetic perceptions of lesbian women about sex shop products follow from a relationship of power with the partner to a relationship of strangeness with the object, generating possible discomfort. Still, both in online research and in face-to-face research, it was possible to identify that there is a preference for phallic sex toys with artificial colors and shapes.

Keywords: Sex toys. Lesbians. Sex-oriented businesses. Pattern perception.

Recebido em: 03/03/2020

Aceito em: 08/12/2020 


\section{INTRODUÇÃO}

A função simbólica do produto pode estar ligada à sua percepção estética. Ao pensar em produtos de sex shop, o design deve ser avaliado com cuidado, já que há distintos públicos para uma mesma gama de produtos (BAXTER, 1998). A fim de analisar fatores estéticos envolvidos na relação entre mulheres e sex toys, este artigo busca entender a percepção estética de mulheres lésbicas acerca de produtos de sex shop. O interesse nesse estudo se dá a partir do entendimento que, estando em uma sociedade patriarcal e heteronormativa ${ }^{1}$, sex toys são projetados, em suma, buscando uma estética falocêntrica e realista, o que nem sempre é necessário ou interessante aos diferentes públicos que utilizam esses produtos. No caso desse estudo, optou-se por entender as percepções estéticas de mulheres lésbicas acerca desses produtos pois, ao pensar em nossa sociedade enquanto machista e falocêntrica, mulheres lésbicas podem ser consideradas duplamente invisibilizadas enquanto mulheres que se relacionam com outras mulheres. $E$, tal qual a sociedade, o design deve repensar e problematizar práticas exclusivamente heterocentradas e heteronormativas. Assim, os produtos de sex shop devem ser elaborados com foco nos usuários.

Esta é uma pesquisa exploratória, básica e descritiva, que se desenvolveu a partir de pesquisa de campo com entrevistas, utilizando um questionário semiestruturado. Esse questionário foi aplicado em grupos focais, de maneira on-line e presencial, sendo a análise desses dados desenvolvida de forma qualitativa.

\section{ESTÉTICA NO DESIGN}

Pode-se considerar que, no design, os sentidos humanos são responsáveis por ativar a percepção estética dos artefatos (KRIPPENDORF, 2006). Ainda, essa percepção pode ser atingida a partir de diferentes níveis de prazer que um objeto pode proporcionar. Deve-se ponderar que tal experiência também pode ser socialmente adquirida, proveniente de experiências e comportamentos (KRIPPENDORF, 2006).

Löbach $(2000$, p. 62) define que um produto deve ser, também, beneficiado de funções estéticas, “[...] atendendo à percepção multissensorial do usuário. Multissensorial porque são ativados todos os sentidos do homem de forma global, sendo raramente possível uma percepção unidimensional". Ainda, o autor explica que há dois fatores essenciais para o uso sensorial dos produtos, sendo esses "[...] as

\footnotetext{
${ }^{1} \mathrm{O}$ termo heteronormatividade é utilizado com o intuito de explicar acontecimentos em que outras orientações sexuais fora da norma padrão (heterossexualidade) são socialmente perseguidas, marginalizadas ou ignoradas.
} 
experiências anteriores com as características estéticas (forma, cor, superfície, som etc.) e a percepção consciente dessas caraterísticas" (LÖBACH, 2000, p. 62).

A função estética faz parte da função simbólica, já que "A função simbólica dos produtos é determinada por todos os aspectos espirituais, psíquicos e sociais do uso" (LÖBACH, 2000, p. 64), ou seja, a função simbólica é representada a partir da função estética.

Deste modo, entende-se que a percepção estética dos produtos é parte fundamental para o desenvolvimento dos mesmos, sendo necessário pesquisar sobre o mind style do público-alvo, buscando um maior entendimento acerca das necessidades e especificidades de cada grupo de indivíduos, para então projetar o que melhor se adequa a eles.

\section{A CONTRASSEXUALIDADE E OS PRODUTOS DE SEX SHOP}

Na sociedade, até então, o padrão considerado 'normal' era aquele em que os indivíduos não expressavam qualquer sexualidade, nem mesmo aquela ligada ao heterossexual. Toda e qualquer conduta sexual ligada unicamente ao prazer era vista como destoante e anormal. Na atualidade, o sexo é visto como desejo e busca por prazer, sendo considerado parte de uma categoria de bens de consumo.

Preciado (2014, p. 27) explica, em seu manifesto contrassexualidade, que é de extrema importância entender os locais ocupados pelos corpos de "[...] intersexuais, hermafroditas, loucas, caminhoneiras, bichas, sapas, bibas, fanchas, butchs, histéricas, saídas ou frígidas, hermafrodykes, reforçando o poder dos desvios e derivações em relação ao sistema heterocentrado". Na indústria erótica, pode-se considerar que os nichos à margem da sociedade estão estereotipados, uma vez que, dado o pouco conhecimento da indústria e dos designers acerca dos novos modos de ser, há a discrepância entre o real e o imaginário sobre esses outros corpos.

A dildotectônica (PRECIADO, 2014) é um termo utilizado para explicar como o dildo modifica o corpo humano que o veste, transformando, esse, em algo místico que transpassa o certo e o errado dentro da lógica normativa, já que, por utilizar um dildo - aqui visto como um objeto plástico falocêntrico - o indivíduo automaticamente entra em um mundo de poder falocentrado, onde o que importa é o falo e não o que há por debaixo dele. Assim, o autor questiona: 
O que é um dildo: um objeto, um órgão, um fetiche...? Devemos considerar o dildo como uma imitação grosseria do pênis? [...] Por acaso o dildo é um sintoma de uma construção falocêntrica do sexo? O que dizer então dos dildos que não são "fálicos" (os que têm a forma de porco, de borboleta ou de sereia, ou que simplesmente não são figurativos?) (PRECIADO, 2014, p. 71).

O autor levanta esses questionamentos para contrapor às ideias padronizadas socialmente sobre o uso de objetos fálicos, onde, mesmo no meio feminista - principalmente na vertente radical do movimento -, o uso de dildos pode ser considerado uma forma de 'imitação' do sexo heterossexual. Ainda, Preciado $(2014$, p. 71) continua a problematizar essa questão quando pergunta "[...] se toda lésbica que utiliza um dildo deve ser considerada como uma machona, sendo o dildo uma imitação fálica que vem compensar uma inveja do pênis, como explicar que os homens gays utilizem dildos?".

A contrassexualidade, para Preciado (2014, p. 413), é uma teoria do corpo situada fora das oposições binárias, assim a sexualidade é definida como tecnologia e o sistema sexo/gênero e suas práticas "não passam de máquinas, produtos, instrumentos, aparelhos, truques, próteses, redes, aplicações, programas, conexões, fluxos de energia e dê informação interrupções e interruptores, chaves, equipamentos, formatos, acidentes, detritos, mecanismos, usos, desvios...". A tecnologia sexual, problematizada por Preciado, propõe pensar o desejo e o prazer como produtos.

Com essas e outras questões, Preciado (2014) compõe seu manifesto contrassexual, que fala sobre novos corpos e vivências que fogem da regra heteronormativa. Assim, passa-se ao tópico de resultados da pesquisa e discussões.

\section{RESULTADOS E DISCUSSÕES}

A pesquisa on-line se desenvolveu a partir de um questionário semiestruturado. Na primeira parte, as seguintes questões deveriam ser respondidas: "Qual seu gênero?" - sendo possível escolher entre 'feminino' e 'masculino' -, "Você mantém relações sexuais com: - sendo possível escolher entre 'mulheres', 'homens' ou 'homens e mulheres' - e "Qual a sua faixa etária?" - sendo possível escolher entre '18-25 anos', '26-35 anos', '36-49 anos' e '+50 anos' -. Ao total, 54 pessoas responderam ao questionário disponibilizado on-line, sendo que, para o escopo desta pesquisa, todas aquelas que marcaram 'masculino' como gênero ou 'homens'/'homens e mulheres' como parceiros sexuais tiveram suas respostas excluídas dos resultados, sendo o número final de respostas consideradas nesta pesquisa como 39 pessoas. 
O grupo de participantes on-line foi formado a partir de compartilhamento do link do formulário. Esse link foi enviado e compartilhado via redes sociais - Twitter, WhatsApp e Facebook - , tendo como foco grupos de pessoas LGBT+. Iniciou-se o compartilhamento em 10 de outubro de 2019, tendo sido o questionário desativado dia 20 de outubro de 2019.

As respostas obtidas de acordo com a faixa etária foram: 17 mulheres afirmaram ter entre 18 e 25 anos, 12 mulheres afirmaram ter entre 26 e 35 anos, 8 mulheres afirmaram ter entre 36 e 49 anos e uma mulher afirmou ter mais de 50 anos. Entende-se que o público desta pesquisa seja, majoritariamente, de mulheres que têm entre 18 e 25 anos, embora isso não queira dizer que os resultados da pesquisa devam ser pensados apenas para esta faixa etária de público, já que, com esse artigo, busca-se compreender a percepção estética um grupo à margem, não sendo necessário marginalizar outros grupos para isto.

Em seguida, questionou-se quais produtos de sex shop as participantes desse estudo já utilizaram ao manter relações sexuais com outras mulheres. Esta pergunta poderia ser respondida com múltipla escolha. As respostas podem ser observadas na Figura 1.

Figura 1 - Respostas obtidas com a questão de múltipla escolha acerca de produtos de sex shop utilizados ao manter relações sexuais com outras mulheres

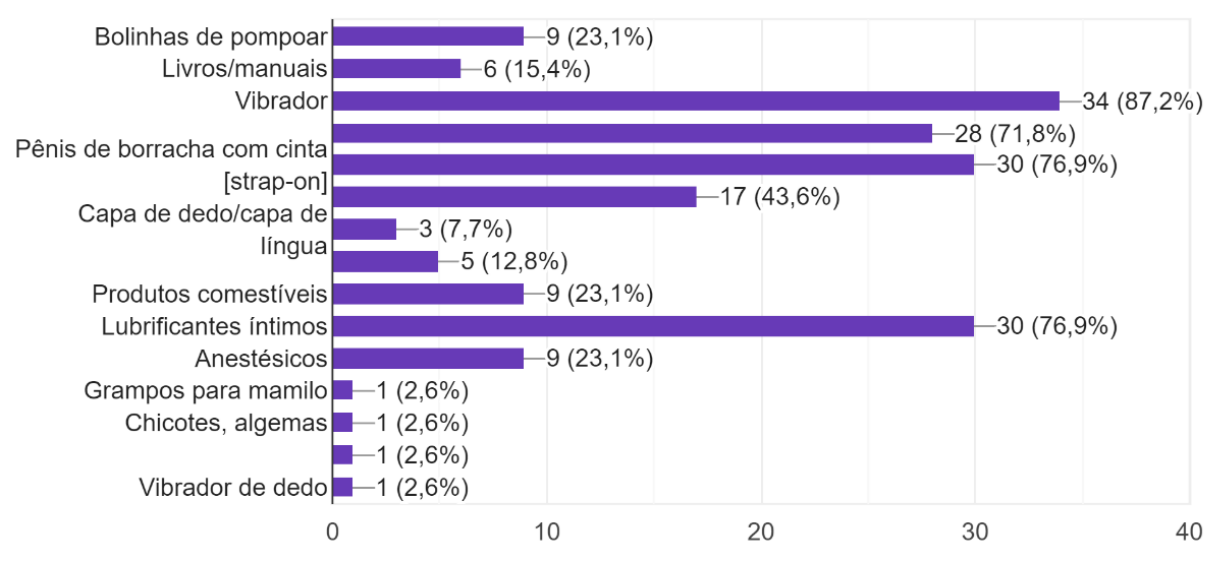

Fonte: os autores (2019).

Assim, entende-se que, dentro das 39 mulheres participantes dessa pesquisa, 34 delas já utilizaram vibradores, 30 delas já utilizaram pênis de borracha com cinta, 30 delas já utilizaram lubrificantes íntimos e 28 delas já utilizaram pênis de borracha sem vibrador. Enquanto isso, 9 utilizaram produtos comestíveis, 5 utilizaram fantasias e apenas 3 utilizaram capa de dedo ou capa de língua - que, inclusive, é recomendado 
pelo Sistema Único de Saúde como possível barreira para algumas ISTs (infecções sexualmente transmissíveis). Com esta pergunta, pode-se perceber que há uma maior preferência por produtos como vibradores ou dildos.

Quando questionadas acerca da estética de produtos de sex shop, 25 participantes afirmaram que preferem produtos com cores e formas artificiais, 9 afirmaram que preferem alguns produtos realísticos e outros artificiais, 4 consideram esteticamente indiferentes e uma afirmou preferir produtos realísticos.

A seguir, foram apresentadas oito figuras de sex toys - sendo estes dildos e vibradores -, com a seguinte proposta: "Dentre os produtos a seguir, defina quais produtos você considera visualmente atrativos, considerando 1 como nada atrativo e 5 como muito atrativo", possibilitando a visualização em escala. Na Figura 2 é possível observar, da esquerda para a direita, quais foram os produtos escolhidos como mais atrativos esteticamente.

Figura 2 - Escala produzida a partir das respostas obtidas com a pergunta "Dentre os produtos a seguir, defina quais produtos você considera visualmente atrativos, considerando 1 como nada atrativo e 5 como muito atrativo"

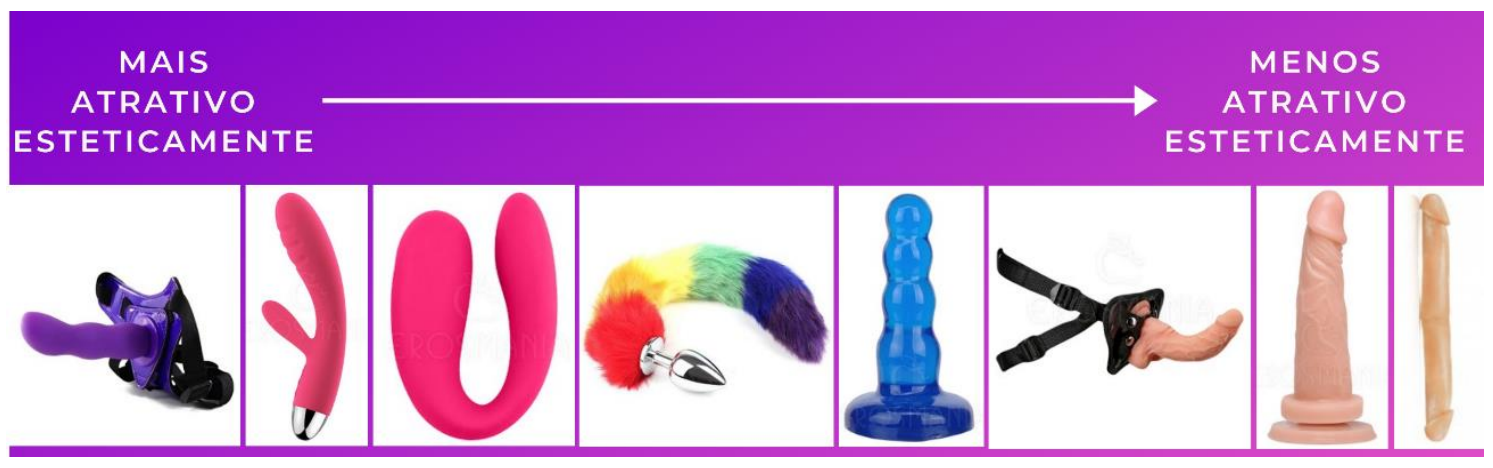

Fonte: os autores (2019).

O questionário presencial contou com as mesmas perguntas, porém com painéis semânticos e visuais que auxiliaram no desenvolvimento de outras respostas. Esse questionário presencial foi aplicado entre transeuntes do Centro de Artes da Universidade do Estado de Santa Catarina, tendo sido abordadas cerca de 50 pessoas entre os dias 10 de outubro de 2019 e 12 de outubro de 2019. Estas pessoas eram convidadas a participar do estudo de forma anônima. Destas 50 pessoas, 7 mulheres foram selecionadas seguindo os critérios anteriormente assinalados: todas aquelas pessoas que marcaram 'masculino' como gênero ou 'homens'/'homens e mulheres' como parceiros sexuais tiveram suas respostas excluídas dos resultados. 
Assim, foram entrevistadas 7 mulheres lésbicas entre 24 e 43 anos. O Quadro 1 demonstra o perfil dessas participantes.

Quadro 1 - Perfil das participantes presenciais da pesquisa

\begin{tabular}{|l|l|}
\hline \multicolumn{1}{|c|}{ Identificação } & \multicolumn{1}{c|}{ Idade } \\
\hline Entrevistada 1 & 24 anos \\
\hline Entrevistada 2 & 33 anos \\
\hline Entrevistada 3 & 30 anos \\
\hline Entrevistada 4 & 27 anos \\
\hline Entrevistada 5 & 26 anos \\
\hline Entrevistada 6 & 43 anos \\
\hline Entrevistada 7 & 36 anos \\
\hline
\end{tabular}

Fonte: os autores (2019).

Quando questionadas sobre os produtos de sex shop que já haviam utilizado ao manter relações sexuais com outras mulheres, todas responderam que já utilizaram vibradores, 6 responderam que já utilizaram pênis de borracha sem cinta e 5 responderam que já utilizaram pênis de borracha com cinta. Ainda, todas afirmaram já terem utilizados lubrificantes íntimos, 3 afirmaram já terem utilizado fantasia e uma afirmou ter utilizado chicotes.

Quando questionadas acerca da estética de produtos de sex shop, 6 afirmaram que preferem produtos esteticamente artificiais e uma respondeu que prefere alguns produtos artificiais e outros realísticos. Quando questionada sobre o motivo da preferência estética, a Entrevistada 6 afirmou que "vibradores eu gosto quando são bem artificiais, mas quando uso cinta, prefiro que seja mais real, sabe? Tem algo sobre o poder que eu sinto que tenho sobre a minha parceira quando uso isso com ela". Já a Entrevistada 3 diz que "não gosto nem de pensar na possibilidade de usar um dildo super realista. Tenho pavor de pensar em qualquer coisa tão parecida com um pênis no meu quarto".

Na sequência, foram apresentadas oito figuras de sex toys - sendo estes dildos e vibradores - , com a seguinte proposta: "Dentre os produtos a seguir, defina quais produtos você considera visualmente atrativos, considerando 1 como nada atrativo e 5 como muito atrativo", possibilitando a visualização em escala. Na Figura 3 é possível observar, da esquerda para a direita, quais foram os produtos escolhidos como mais atrativos esteticamente. 
Figura 3 - Escala produzida a partir das respostas obtidas com a pergunta "Dentre os produtos a seguir, defina quais produtos você considera visualmente atrativos, considerando 1 como nada atrativo e 5 como muito atrativo"

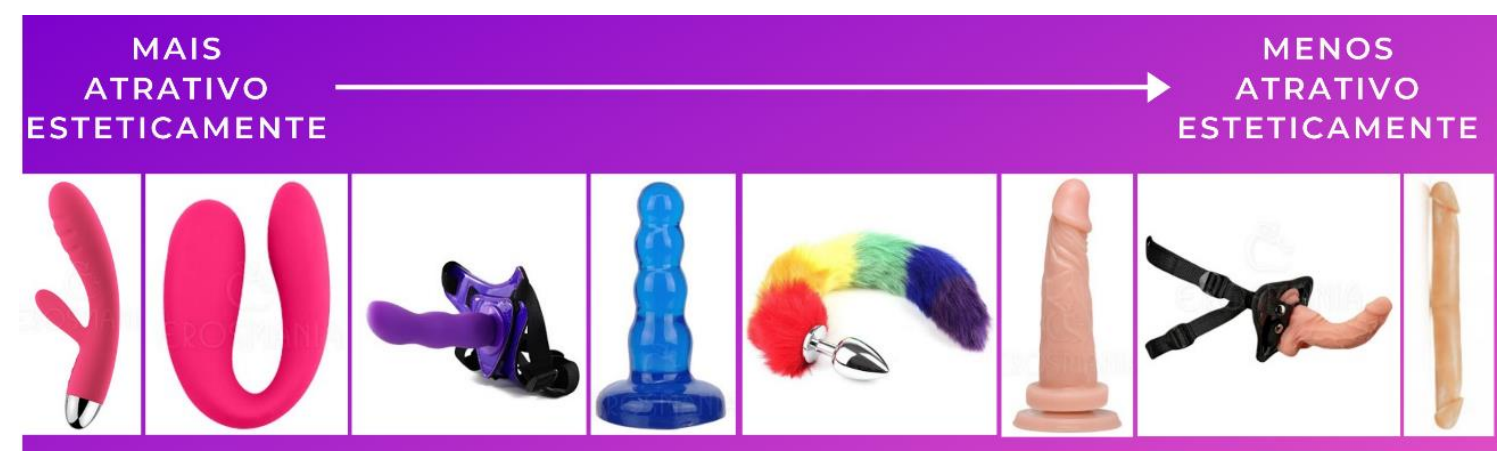

Fonte: os autores (2019).

Com o questionamento utilizando os painéis semânticos dessa última questão, algumas respostas foram obtidas. A Entrevistada 1 disse que "o plug anal de arco-íris é a maior prova que pink money² dá dinheiro sim pra quem faz os produtos de sex shop, não entendo a dificuldade de fazer uns consolos mais bonitinhos pras lésbicas". A Entrevistada 5 afirmou que "depois dessas fotos, tenho total certeza que não gosto de pênis". A Entrevistada 7 disse que "sempre achei as lojas de sex shop um local de sátira, nunca um local de prazer". Ainda, a Entrevistada 2 disse que "acho muito agressivo pensar em dildos realistas. Me sinto meio estranha ao pensar nisso".

Preciado (2014) questiona sobre os limites entre o corpo e o dildo, como identificar o sujeito que utiliza um dildo e como é possível falar sobre substituições a partir do objeto:

[...] Onde se encontra o sexo de um corpo que usa um dildo? O dildo, em si, é um atributo feminino ou masculino? Onde transcorre o gozo quando se transa com um dildo? Quem goza? Quantos pênis tem um homem que usa um dildo? Se o dildo não é mais do que um "substituto artificial" do pênis, como explicar que os homens que já têm um pênis utilizem cintas penianas? (PRECIADO, 2014, p. 71).

A aparência do produto pode atuar, negativamente ou positivamente, sobre o sujeito-usuário ou o observador, sendo passível que ocasione um sentimento de aceitação ou rejeição (LÖBACH, 2000). Assim, entende-se que as percepções estéticas de mulheres lésbicas acerca de produtos de sex shop não sejam apenas suas, já que os produtos são, muitas vezes, compartilhados com suas parceiras sexuais. Best (2012) explica que, geralmente, o design é idealizado como aquilo que irá “[...] preencher (ou superar) suas

\footnotetext{
2 Pink money é o termo utilizado para definir o valor gasto de um novo nicho de mercado: o público LGBT. Sendo visto como um novo nicho disposto a gastar dinheiro com representatividade, é possível encontrar produtos desenvolvidos para pessoas LGBTs a partir de diferentes mercados.
} 
necessidades e expectativas" (BEST, 2012, p. 28). No caso deste estudo, foi possível identificar que as percepções estéticas de mulheres lésbicas acerca de produtos de sex shop seguem desde uma relação de poder com a parceira, conforme descrito pela Entrevistada 6, até uma relação de estranheza com o objeto, gerando possíveis desconfortos. Ainda, tanto na pesquisa on-line quanto na pesquisa presencial, foi possível identificar que há uma preferência por sex toys fálicos e com cores e formas artificiais.

Sobre a preferência por sex toys fálicos, pode-se pensar na seguinte fala de Preciado (2014, p. 71): “E qual é a relação estrutural entre uma cinta peniana e um cinto de castidade?". Entende-se que, objetos fálicos, cintas penianas e demais sex toys são parte da biopolítica do sexo (PRECIADO, 2014), que molda socialmente os sujeitos para se adaptarem às novas políticas do corpo. Ou seja, enquanto objeto fálico ou não, não há uma distinção entre o ser ou não ser, já que, de qualquer forma, os usuários serão socialmente subjugados à orientação sexual deles.

\section{CONSIDERAÇÕES FINAIS}

A partir da fundamentação teórica, da pesquisa e dos resultados da mesma, considera-se que foi possível entender quais as percepções estéticas de mulheres lésbicas acerca de produtos de sex shop. Ainda, embora todas as respostas tenham sido anônimas, é possível considerar que tanto o questionário on-line quanto o presencial foram interessantes para problematizar diferentes vivências. Quando se fala de sexualidade, orientação sexual e práticas sexuais, é importante entender que os sujeitos, por mais verdadeiros que sejam, estão alcançando suas subjetividades mais profundas, podendo interferir drasticamente nas respostas produzidas.

Estas e outras questões foram postas à prova durante o desenvolvimento desta pesquisa. Em princípio, e com certo receio de marginalizar outros grupos, buscou-se abrir o escopo da pesquisa para todas as mulheres que se relacionavam sexualmente com outras mulheres, sendo lésbicas, bissexuais ou sem uma definição específica de sexualidade. Isto pois, conforme estudos recentes - principalmente de Paul Preciado -, entende-se que a sexualidade é muito mais fluida que fixa, muito mais mutável que unicamente constante. Ainda assim, e no escopo de pesquisa de design, os autores deste trabalho entendem como necessária - principalmente em uma circunstância política e social - a devida nomenclatura aos grupos marginalizados. É preciso reafirmar a necessidade de entendimento da existência de mulheres lésbicas. 


\section{REFERÊNCIAS}

BAXTER, M. Projeto de produto: guia prático para o design de novos produtos. 2. ed. São Paulo: Edgard Blüncher, 1998.

BEST, K. Fundamentos de gestão do design. Porto Alegre: Bookman, 2012.

LÖBACH, B. Design industrial. São Paulo: Edgard Blucher, 2000.

KRIPPENDORFF, K. The semantic turn: A new foundation for design. Boca Raton, FL: CRC Press, 2006.

PRECIADO, B. Manifesto contrassexual: Políticas subversivas de identidade sexual. São Paulo: $n-1$ edições, 2014. 